\title{
FGF2 Promotes Msx2 Stimulated PC-1 Expression Via Frs2/MAPK Signaling
}

\author{
Yan Li, ${ }^{1}$ Jin Liu, ${ }^{2}$ Mark Hudson, ${ }^{3}$ Sungsu Kim, ${ }^{2}$ and Nan E. Hatch ${ }^{2 *}$ \\ ${ }^{1}$ Department of Periodontics and Oral Medicine, University of Michigan, Ann Arbor, Michigan \\ ${ }^{2}$ Department of Orthodontics and Pediatric Dentistry, University of Michigan, Ann Arbor, Michigan \\ ${ }^{3}$ Department of Physiology and Biophysics, University of Washington, Seattle, Washington
}

\section{ABSTRACT}

PC-1 is an enzymatic generator of pyrophosphate and a critical regulator of tissue mineralization. We previously showed that fibroblast growth factor-2 (FGF2) specifically induces PC-1 expression in calvarial pre-osteoblasts and that this occurs via a transcriptional mechanism involving Runx2. Because aberrant FGF signaling and Msx2 activity result in similar craniofacial skeletal defects and because Msx2 is an established regulator of osteoblastic gene expression, here we investigate Msx2 as an additional mediator of PC-1 gene expression. mRNA analysis and experiments utilizing PC-1 gene promoter/luciferase reporter constructs demonstrate that Msx2 promotes transcription of the PC-1 gene downstream of FGF2. Results indicate that both Msx2 and Runx2 are recruited to a conserved core Msx2 binding site within the PC1 gene promoter upon FGF2 stimulation, and that Msx2 and Runx2 function together to induce PC-1 gene expression in osteoblastic cells. Here we show that FGF signaling promotes Msx2 transcriptional activity on the PC-1 gene promoter via the Frs2/MAPK signaling pathway. To our knowledge, this is the first report of Msx2 functioning as a transcriptional enhancer downstream of FGF2 in calvarial pre-osteoblasts. As activating mutations in FGF receptors and Msx2 result in similar craniofacial skeletal disorders, our findings support the idea that FGF signaling and Msx2 activity influence cranial osteogenesis via the same molecular mechanism. J. Cell. Biochem. 111: 1346-1358, 2010. (c) 2010 Wiley-Liss, Inc.

KEY WORDS: FIBROBLAST GROWTH FACTOR; MSX2; RUNX2; OSTEOBLAST; PC-1/ENPP1; FRS2; MAPK

$\mathrm{F}$ ibroblast growth factor receptors (FGFR's) are receptor tyrosine kinases whose normal activity is critical for the development of multiple tissue types, including the craniofacial skeleton. Upon activation, FGFR's elicit downstream signaling via receptor dimerization, auto-phosphorylation and recruitment of docking and signaling proteins at the plasma membrane. FGFR1 and FGFR2 can directly bind to activate PLC $\gamma 1$, and can indirectly activate the Ras/Raf/MEK/MAPK signaling pathway [Mohammadi et al., 1996]. Ras activation is achieved through recruitment and activation of the docking protein Frs2, followed by binding and activation of adaptor proteins Grb2, Shp2, and Sos1 [Ridyard and Robbins, 2003]. MAPK activation can also be stimulated via Frs2 bound, atypical PKC's (PKC $\lambda$ and PKC $\zeta$ ) [Berra et al., 1995; Lim et al., 1999]. In either scenario, MAPK activation is dependent upon the binding and activation of Frs2 by the FGF receptor. Upon phosphorylation, MAPK translocates to the nucleus where it functions to regulate gene expression by phosphorylating transcription factors [Thisse and Thisse, 2005]. Relevant to FGF signaling effects on skeletal development, MAPK was previously shown to mediate osteoblast specific gene expression via phosphorylation of the osteoblast master transcription factor, Runx2 [Ge et al., 2009].

Activating mutations in FGF receptors are associated with a series of human malformation disorders with a primary phenotype of craniosynostosis. Craniosynostosis is a debilitating clinical condition characterized by the premature fusion of cranial bones. This premature fusion results in an aberrant skull shape and increased intracranial pressure due to limited growth at areas of cranial bone fusion. The prevalence of craniosynostosis is high, at approximately 1 in 2,500 live births, and current treatment is limited to genetic counseling, surgery, dental, medical, and social support. Morbidity for craniosynostosis is also high, in that many patients require multiple craniofacial surgeries throughout childhood for normalization of craniofacial shape and relief of high intracranial pressure. While it has been known for over a decade that craniosynostosis is associated with activating mutations in FGFR's, the precise

Additional Supporting Information may be found in the online version of this article.

*Correspondence to: Nan E. Hatch, Department of Orthodontics and Pediatric Dentistry, 1011 N University Avenue, University of Michigan, Ann Arbor, MI 48109-1078. E-mail: nhatch@umich.edu

Received 10 June 2009; Accepted 18 August 2010 • DOI 10.1002/jcb.22861 • (c) 2010 Wiley-Liss, Inc.

Published online 27 August 2010 in Wiley Online Library (wileyonlinelibrary.com). 
molecular mechanism by which these mutations lead to the disease phenotype is unknown. Notably, activating mutations in Msx2 are also associated with the development of craniosynostosis [Jabs et al., 1993] but it is unknown if mutations in Msx2 or FGF receptors lead to craniosynostosis via the same molecular mechanism.

Recent studies indicate that local inorganic phosphate (Pi) to pyrophosphate (PPi) concentration ratios, as mediated by differential expression of the enzymes PC-1 (Enpp1) and tissue nonspecific alkaline phosphatase (TNAP), control tissue mineralization [Murshed et al., 2005]. PC-1 is the primary enzymatic generator of PPi by mineralizing cells [Johnson et al., 1999]. TNAP hydrolyzes PPi to Pi and TNAP activity is essential for hydroxyapatite crystal deposition and growth [Anderson et al., 2004]. The influence of PC-1 and TNAP on tissue mineralization can be explained by their ability to influence PPi and Pi levels. PC-1 increases extracellular PPi, which inhibits hydroxyapatite crystal deposition [Fleisch et al., 1966; Register and Wuthier, 1985; Johnson et al., 1999]. Yet PC-1 generated PPi also serves as an essential source of Pi to enhance mineralization when it is hydrolyzed by TNAP [Johnson et al., 1999, 2000, 2003; Hessle et al., 2002]. Additionally, while physiologic PPi levels inhibit soft tissue calcification, excessive PPi can promote the pathologic calcification of non-bony tissues in the form of calcium pyrophosphate dihydrate (CPPD) crystals [Terkeltaub et al., 1994; Terkeltaub, 2001; Johnson et al., 2001a,b; Johnson and Terkeltaub, 2005]. A cross of the TNAP ${ }^{-I-}$ mouse with the Enpp $1^{-I-}\left(\mathrm{PC}-1^{-I-}\right)$ mouse generates a double knockout mouse with apparently normal calvarial mineralization, supporting the idea that PC-1 and TNAP work together to produce normally mineralized bone matrix via the elaboration and hydrolysis of PPi [Hessle et al., 2002]. Significantly, closer inspection of the Enpp $1^{-/-} / \mathrm{TNAP}^{-/-}$double knockout mice revealed persistent hypomineralization of long bones, indicating that PC-1 and TNAP play distinct roles in the mineralization process, dependent upon skeletal tissue type [Anderson et al., 2005]. Because calvarial cells express significantly more PC- 1 than cells from long bones [Anderson et al., 2005], these findings may also indicate that PC-1 is more central to the process of calvarial mineralization than long bone mineralization. Notably, craniosynostosis is seen in up to $78 \%$ of infants with inactivating mutations in TNAP, but it is unknown how diminished TNAP activity leads to craniosynostosis [Wenkert et al., 2009]. Because TNAP hydrolyzes PC-1 generated PPi to $\mathrm{Pi}$, patients with inactivating mutations in TNAP exhibit hyperpyrophosphatemia. It is unknown if TNAP-associated craniosynostosis is mediated by the high pyrophosphate levels seen in these patients.

Because inorganic PPi to Pi concentration ratios regulate tissue mineralization and because activating mutations in FGF receptors are associated with abnormal craniofacial skeletal development including craniosynostosis, we hypothesized that FGF signaling regulates expression of factors that control the generation and hydrolysis of PPi. Initial results of this investigation demonstrated that FGF signaling induced PC-1 and inhibited TNAP expression in MC3T3E1(C4) calvarial cells [Hatch et al., 2005]. This combined pattern of gene expression is expected to increase extracellular levels of PPi and diminish extracellular levels of Pi. Concordant with changes in gene expression, continuous FGF2 treatment inhibited hydroxyapatite formation. These results indicated that FGF signaling may influence bone mineralization via changes in the generation and hydrolysis of pyrophosphate. To substantiate these results, we subsequently showed that FGF2 stimulated expression of PC-1 while inhibiting expression of TNAP in primary calvarial cells and bone marrow stromal cells. We also showed that the induction of PC-1 gene expression in calvarial pre-osteoblasts by FGF signaling is direct and is mediated by the master transcriptional regulator of osteoblast differentiation, Runx2 [Hatch et al., 2009]. Notably, mutation of all four Runx2 binding sites in the proximal PC-1 gene promoter reduced but did not eliminate promoter responsiveness to FGF2. This finding indicated the likely involvement of additional factors. Because regulation of PC-1 gene expression may be a primary mechanism for controlling craniofacial bone mineralization and because Msx2 was previously shown to regulate Runx2 transcriptional activity downstream of FGF2 [Shirakabe et al., 2001], here we investigate Msx2 as an additional mediator of FGF stimulated PC-1 gene expression.

We find that Msx2 functions as a transcriptional enhancer of PC1 gene expression downstream of FGF2 in calvarial pre-osteoblasts. Results indicate that Msx2 and Runx2 likely function together to induce PC-1 gene expression in osteoblastic cells and demonstrate that FGF signaling stimulates Msx2 transcriptional activity through the Frs2 mediated MAPK signaling pathway.

\section{MATERIALS AND METHODS}

\section{CELL CULTURE AND TREATMENTS}

The mTERT immortalized calvarial cell line from Runx2-null mice [Bae et al., 2007] was a gift from Dr. Jane Lian (Univ. of Massachusetts School of Medicine). MC3T3E1(C4) and C3H10T1/2 were a gift from Dr. Renny Franceschi [Univ. of Michigan School of Dentistry; Phimphilai et al., 2006]. MC3T3E1(C4) cells have been shown to exhibit high osteoblastic differentiation potential upon addition of ascorbate [Sudo et al., 1983; Wang et al., 1999]. C3H10T1/2 is a murine mesenchymal pluripotent cell line [Taylor and Jones, 1979]. MC3T3E1(C4), C3H10T1/2, and Runx2-null cells were cultured in custom formulated $\alpha$ MEM containing no ascorbate (Invitrogen), supplemented with 10\% fetal bovine serum (FBS) and $10,000 \mathrm{mg} / \mathrm{ml}$ penicillin/streptomycin (P/S). Non-osteoblastic COS7 cells were cultured in DMEM supplemented with 10\% FBS and P/S. Recombinant FGF2 (Peprotech) was added to a final concentration of $50 \mathrm{ng} / \mathrm{ml}$ in $\alpha$ MEM media containing 0.5\% FBS. U0126 (Sigma) was added to a final concentration of $10 \mu \mathrm{M}$.

\section{TRANSFECTIONS}

Superfect transfection reagent (Qiagen) was utilized for all transfection experiments, following manufacturer's recommended protocol. Briefly, cells were incubated with DNA/Superfect complexes for $4 \mathrm{~h}$ in media containing 10\% FBS and penicillin/ streptomycin. After washing, cells were incubated for an additional $48 \mathrm{~h}$ prior to cytokine treatment or cell lysis.

\section{DNA CONSTRUCTS}

The $2.8 \mathrm{~kb}$ proximal PC-1 gene promoter/firefly luciferase construct was previously described [Hatch et al., 2009]. This gene promoter region contains four potential Runx 2 binding sites and one potential 


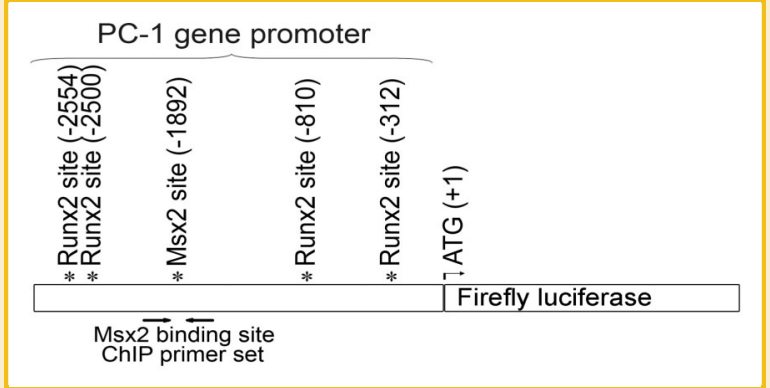

Fig. 1. PC-1 gene promoter/firefly luciferase construct. A $2.8 \mathrm{~kb} 5^{\prime}$ untranslated region of the PC-1 gene was cloned by PCR and ligated into the PGL4 firefly luciferase reporter vector to create PGL4/PC-1. Four Runx2 binding sites are present within the promoter sequence, two within a distal region of the promoter and two within a more proximal region. A conserved Msx2 binding site is also present within the promoter. Also indicated are primers designed to amplify the Msx2 binding site region for chromatin immunoprecipitation (ChIP) analysis. This primer set was utilized to establish that both Msx2 and Runx2 bind to the PC-1 gene promoter in this region (Fig. $5 C, D$ ).

Msx2 binding site (Fig. 1). pCMV5/LacZ and pCMV5/Runx2 expression vectors were previously described [Willis et al., 2002]. pcDNA3/Msx2 expression vector was a generous gift by Dr. Jane Lian [University of Massachusetts School of Medicine; Hassan et al., 2006]. FGFR $2^{\mathrm{C} 278 \mathrm{~F}}$ constructs were previously described [Hatch et al., 2006]. The constructs contain full length FGFR2IIIc (genbank NM_000141) and a Crouzon craniosynostosis syndrome associated mutation that results in ligand independent receptor signaling. FGFR2 ${ }^{\mathrm{C} 278 \mathrm{~F}} /$ Frs2D lacks juxtamembrane valine and threonine residues (at positions 428,429) and cannot bind to Frs2. FGFR2 ${ }^{\mathrm{C} 278 \mathrm{~F}} / \mathrm{KD}$ contains an inactivating mutation in the intracellular kinase domain and cannot auto-phosphorylate.

\section{MUTAGENESIS}

PCR based in vitro mutagenesis was performed utilizing primer $5^{\prime}$ CAGTAGAAACGTCATTCCTTGCTTTGGGTTGCTGAC-3' to mutate the putative Msx2 core binding site located at site -1882 to -1877 within the murine proximal PC-1 gene promoter from $5^{\prime}$ TAATTG-3' to $5^{\prime}$-TCCTTG-3' (mutation in italics). Msx 2 cannot bind to this mutated site.

\section{MRNA QUANTIFICATION}

RNA was isolated using Trizol reagent (Invitrogen) following manufacturer protocol. mRNA levels were assayed by reverse transcription and real time PCR. Real time PCR was performed utilizing the murine PC-1 primer/probe set Mm01193752_m1, the murine GAPDH primer/probe set Mm9999915_g1, the murine Msx2 primer/probe set Mm00442992_m1, the murine Runx2 primer/ probe set Mm00501578_m1, and Taqman Universal PCR Master Mix (Taqman Gene Expression Assays, Applied Biosystems). Real-time PCR was performed on a GeneAmp 7700 thermocyler (Applied Biosystems) and quantified by comparison to a standard curve. PC1, Msx2, and Runx2 mRNA levels are reported after normalization to $\beta$-actin or GAPDH mRNA levels. Statistical significance between samples was determined by Student's $t$ test with a probability value of $P<0.05$.

\section{LUCIFERASE ASSAYS}

Luciferase expression was assayed using the Dual Glo Luciferase Assay System (Promega) following manufacturer protocol. Cells were co-transfected with experimental firefly and control renilla luciferase constructs. Twenty-microliter aliquots of cell lysate were combined with $100 \mu$ l of luciferase assay substrate and $100 \mu \mathrm{l}$ of Dual glo (Promega) for measurement of firefly and renilla luciferase activity. Firefly luciferase activity was normalized to renilla luciferase activity in order to account for potential differences in transfection and/or cell lysis efficiency. Statistical significance between samples was determined by Student's $t$ test with a probability value of $P<0.05$.

\section{SHRNA TRANSDUCTIONS}

Lentiviral particles containing an Msx2 or Runx2 specific shRNA sequence cloned into the pLKO.1 lentiviral vector (Sigma Mission, St. Louis, M0) was utilized to knock down expression of Msx2 or Runx2 mRNA, respectively. Lentiviral particles containing nontarget shRNA (SHC002) were utilized as a negative control. MC3T3E1(C4) cells were plated for approximately 70\% confluence then transduced with lentiviral particles at a multiplicity of infection equal to five, in the presence of $8 \mu \mathrm{g} / \mathrm{ml}$ hexadimethrine bromide. Successfully transduced cells were selected in media containing $10 \mu \mathrm{g} / \mathrm{ml}$ puromycin, then tested for suppression of Msx2 or Runx2.

\section{NUCLEAR EXTRACTIONS}

Nuclei were isolated and nuclear extract was purified as previously described [Roca et al., 2005]. MC3T3E1(C4) cells were treated with $50 \mathrm{ng} / \mathrm{ml} \mathrm{FGF2}$ for $12 \mathrm{~h}$. Cells were lysed in hypotonic buffer and homogenized with a type B pestle. Cell lysis was monitored by trypan blue staining. Lysed cells were then centrifuged and resuspended in a low salt buffer on ice. An equivalent volume of high salt buffer was added and cells were incubated for $30 \mathrm{~min}$ with gentle rotation at $4{ }^{\circ} \mathrm{C}$. Nuclear pellets were centrifuged for $30 \mathrm{~min}$ at $25,000 \mathrm{~g}$ and dialyzed against 50 volumes of dialysis buffer. Nuclear extract was then centrifuged for $20 \mathrm{~min}$ at $25,000 \mathrm{~g}$, aliquoted and stored at $-80^{\circ} \mathrm{C}$.

\section{ELECTROPHORETIC MOBILITY SHIFT ASSAYS}

Double stranded DNA oligonucleotides were designed to include 20 base pairs of the PC-1 promoter sequence surrounding the potential Msx2 binding site. Each oligonucleotide was designed to include a two-guanine overhang for ${ }^{32} \mathrm{P}$-dCTP labeling $\left(5^{\prime}\right.$-ACGTCATTAATTGCTTTGGG-3'). Mutant PC-1 promoter Msx2 binding site oligonucleotides were also designed for this assay (5'-ACGTCATTCCTTGCTTTGGG-3'; mutation in italics). These mutant oligonucleotides include the same DNA mutations that were incorporated into the PGL4/PC1 luciferase construct to eliminate the ability of Msx2 to bind to this site.

Electrophoretic mobility shift assays were performed as previously described [Roca et al., 2005]. Duplexed oligonucleotide was labeled with ${ }^{32} \mathrm{P}-\mathrm{dCTP}$, purified on G-50 columns (Amersham), and verified for radioactivity by scintillation counting. Radiolabeled 
oligonucleotides were incubated with $10 \mu \mathrm{g}$ of nuclear extract and $0.1 \mu \mathrm{g} / \mathrm{ml}$ poly $\mathrm{dI}-\mathrm{dC}$ for $15 \mathrm{~min}$ at room temperature. Samples were then loaded and separated on 10\% Tris-Borate-EDTA buffered acrylamide gels at $4{ }^{\circ} \mathrm{C}$. For supershift assays Msx2 (sc-17729 and sc17731, Santa Cruz), Xpress tag (R91025, Invitrogen) or control IgG (sc-2027, Santa Cruz) antibody was added to the binding reaction prior to gel electrophoresis.

\section{CHROMATIN IMMUNOPRECIPITATION ASSAY (CHIP)}

Chromatin immunoprecipitation assays were conducted as previously described [Roca et al., 2005]. Ten micrograms chromatin (input DNA) and $2 \mu \mathrm{g}$ of Msx2 antibody, Runx2 antibody (D130-3, MBL International) or control IgG antibody were used for each reaction (Santa Cruz). PCR was performed using primers generated to detect the $\mathrm{PC}-1$ promoter region containing the putative Msx2 binding site (5'-CAACTTGCTCTCTTTCTGTCTTGT-3', 5'-CGAATAAGTGTATTGTCAGCAACC-3').

\section{PROTEIN IMMUNOBLOTS}

Cells were lysed in RIPA buffer (50 mM Tris-Cl pH 7.4, $150 \mathrm{mM} \mathrm{NaCl}$, 1\% Nadeoxycholate, 1\% Triton X-100, 0.1\% SDS) containing $1 \times$ protease inhibitor cocktail (Sigma) for western blots. Cells were lysed in IP buffer (Tris buffered saline with 1\% Triton X) containing $1 \mathrm{x}$ protease inhibitor cocktail (Sigma) for immunoprecipitation. For immunoprecipitation, indicated antibody and protein A-sepharose was added to pre-cleared cell lysate and samples were incubated overnight. Immunoprecipitated proteins were released from beads by boiling in Laemmli buffer. Protein samples were separated by SDS polyacrylamide gel electrophoresis and transferred to Immobilon (Millipore). Immunoreactive protein bands were visualized incubation with indicated antibodies followed by enhanced chemiluminescence (Pierce). Anti-phospho-erk1,2 and anti-erk1,2 antibodies were obtained from Cell Signaling (4695, 9101). Horseradish peroxide conjugated secondary anti-mouse and antirabbit antibodies were obtained from Jackson Laboratories. Rabbit anti-V5 antibody was obtained from Bethyl (A190-120A). Antiphospho-tyrosine antibody was obtained from Upstate Biologicals (4G10).

\section{RESULTS}

\section{ANALYSIS OF THE PROXIMAL PC-1 GENE PROMOTER}

We previously showed that the proximal $5^{\prime}$-untranscribed region of the murine PC-1 gene contains four consensus Runx2 binding sites and that Runx2 mediates the induction of PC-1 by FGF signaling. Mutation of all four Runx2 binding sites in the proximal PC-1 gene promoter reduced but did not eliminate promoter responsiveness to FGF2. This finding indicated the involvement of other factors. Subsequent promoter sequence analysis revealed a consensus core Msx2 binding site that is conserved between mouse (position -1892) and human (position -1021) PC-1 gene sequences (Fig. 1).

\section{MSX2 MEDIATES FGF2 INDUCED PC-1 EXPRESSION}

Msx2 commonly acts as a transcriptional repressor and has been shown to inhibit the ability of Runx2 to drive transcription downstream of FGF2 [Dodig et al., 1996; Newberry et al., 1997; Shirakabe et al., 2001; Barnes et al., 2003; Kim et al., 2004; Hassan et al., 2006]. For this reason, we hypothesized that mutation of the Msx2 site within the PC-1 gene promoter might uncover a more dramatic effect of Runx2 on PC-1 promoter activity downstream of FGF2. Surprisingly, mutation of the Msx2 DNA binding site (to prevent binding of Msx2 to this site) inhibited (as opposed to enhanced) PC-1 promoter activity in FGF2 treated MC3T3E1(C4) calvarial pre-osteoblast cells (Fig. 2A). This result indicated that Msx 2 acts to enhance PC-1 gene expression. To substantiate this, we next examined PC-1 mRNA expression in response to Msx2 and FGF2. Results showed that Msx2 significantly increased PC-1 mRNA levels in response to FGF2 in $\mathrm{C}_{310 \mathrm{~T} 1 / 2}$ osteoblast precursor cells (Fig. 2B). Because we previously showed that Runx2 drives PC-1 gene promoter activity, we next investigated Runx2 expression levels in these cells. Results demonstrate that Runx2 mRNA levels were not increased by treatment with FGF2 or by transfection with Msx2. Msx2 transfection in fact led to diminished Runx2 mRNA expression (Fig. 2C). This indicates that the induction of PC- 1 by FGF2 and Msx2 is not mediated by increased Runx2 expression. Msx2 mRNA levels were also not increased by treatment with FGF2 (Fig. 2D), indicating that the induction of PC-1 by FGF2 is not likely mediated by increased Msx2 expression.

We next examined PC-1 promoter activity in response to Msx2 alone or in combination with Runx2. Results demonstrated increased PC-1 promoter response to FGF2 upon expression of Msx2 in MC3T3E1(C4) cells. Combined expression of Runx2 with Msx2 resulted in a synergistic increase in PC-1 promoter activity in response to FGF2 (Fig. 2E). These results indicated that Msx2 functions as a transcriptional enhancer of the PC-1 gene downstream of FGF2 in pre-osteoblast cells, and that Runx2 and Msx2 may function together in this process. Of note, neither FGF2 treatment nor exogenous Runx2 increased expression levels of Msx2, and neither FGF2 treatment nor exogenous Msx2 increased expression levels of Runx2 in these cells (Fig. 2F,G). Similar to results from $\mathrm{C}_{310 \mathrm{~T}} 1 \frac{2}{2}$ cells, transfection with Msx2 led to diminished endogenous Runx2 expression in MC3T3E1(C4) cells (Fig. 2F).

\section{MSX2 SUPPRESSION DIMINISHES ENDOGENOUS PC-1 PROMOTER RESPONSE TO FGF2}

To determine if Msx2 is required for the induction of PC-1 gene expression downstream of FGF2, we next examined PC-1 mRNA levels in MC3T3E1(C4) cells in which Msx2 gene expression was suppressed by shRNA. Results show that cells transduced with shRNA against Msx2 express significantly diminished Msx2 mRNA (Fig. 5A). When treated with FGF2, these cells express significantly reduced PC-1 mRNA when compared to cells expressing non-target shRNA (Fig. 5B). It is important to note here that Msx2 expression was suppressed in Msx2 shRNA expressing cells by approximately 50\%. These results therefore indicate that maximal Msx2 expression is required for maximal induction of PC-1 gene expression by FGF2 treatment. Complete suppression of Mxs2 expression would be required to determine if Msx2 is absolutely required for expression of PC-1.

Because Runx 2 mediates expression of PC- 1 downstream of FGF signaling in osteoblastic cells, we also examined Runx2 

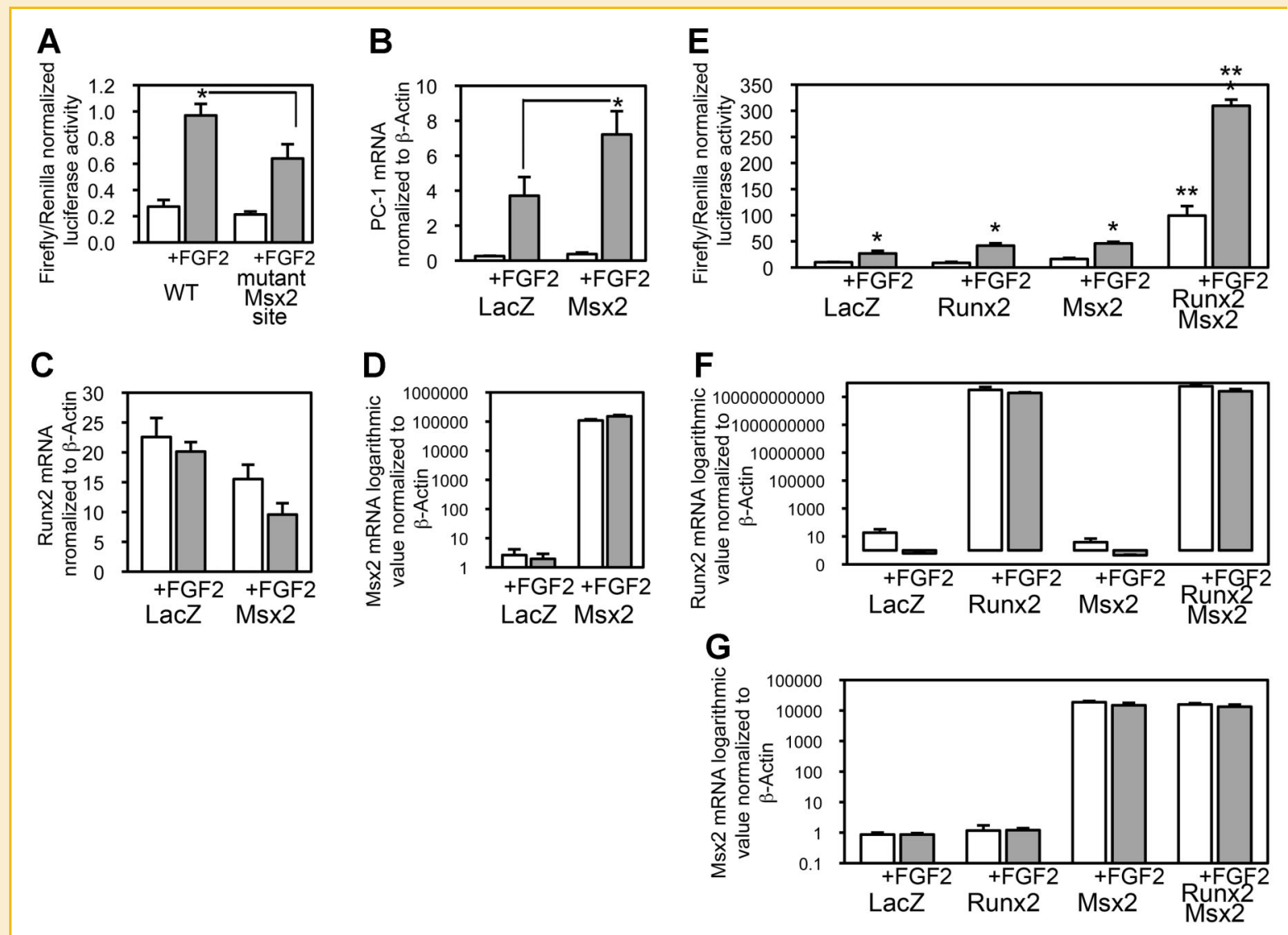

Fig. 2. Msx2 stimulates PC-1 gene expression downstream of FGF2. A: Abolishment of the Msx2 binding site significantly diminishes PC-1 promoter response to FGF2. MC3T3E1 (C4) calvarial pre-osteoblasts were transfected with wild-type PGL4/PC1 or Msx2 binding site mutant PGL4/PC1 and control renilla luciferase constructs, treated with FGF2 for $24 \mathrm{~h}$ and analyzed for luciferase activity. ${ }^{*} \boldsymbol{P}<0.05$ between indicated groups. B: Msx2 enhances FGF2 stimulated PC-1 expression. C310T $1 / 2$ mesenchymal precursor cells were transfected with LacZ or Msx2 expression vectors and treated with FGF2 for $12 \mathrm{~h}$ prior to $\mathrm{mRNA}$ isolation. PC-1 mRNA levels were measured by real-time PCR and PC1 mRNA levels are presented as normalized to $\beta$-actin ${ }^{*} P<0.05$ versus LacZ. C: Transfection with Msx2 and/or treatment with FGF2 do not increase Runx2 mRNA levels in C310T $1 / 2$ cells. Runx 2 mRNA levels of samples shown in (B) are presented as normalized to $\beta$-actin. D: FGF2 treatment does not increase Msx 2 levels in C310T $1 / 2$ cells. Logarithmic values for Msx2 mRNA levels of samples shown in (B) are presented as normalized to $\beta$-actin. E: Runx2 and Msx2 co-expression lead to synergistic increases in PC-1 promoter response to FGF2. MC3T3E1(C4) cells were transfected PGL4/PC1 firefly and control renilla luciferase constructs, and expression vectors for LacZ, Runx2, Msx2, or Runx2 and Msx2 then treated with FGF2 for $24 \mathrm{~h}$ prior to cell lysis for luciferase assay. ${ }^{*} P<0.05$ versus LacZ/no treatment; ${ }^{* *} P<0.05$ versus LacZ/+ FGF2. F: Transfection with Msx2 and/or treatment with FGF2 do not increase Runx2 mRNA levels in MC3T3E1(C4) cells. Logarithmic values for Runx2 mRNA levels of samples shown in (E) are presented as normalized to $\beta$-actin. G: Logarithmic values for Msx2 mRNA levels of samples shown in (E) are presented as normalized to $\beta$-actin.

expression levels in the non-target and Msx2 shRNA expressing cells. Runx2 expression was not significantly different between these cell populations, indicating that the diminished induction of PC-1 in Msx2 shRNA expressing cells is not mediated by changes in Runx2 levels (Fig. 3C). Notably, FGF2 treatment diminished Runx2 expression in cells expressing either non-target and Msx2 targeted shRNA. This is similar to the effect of FGF2 on endogenous Runx2 levels in wild-type MC3T3(E1)C4 wild-type cells seen in other experiments in this cell type [Fig. 2F; Hatch et al., 2009]. This finding again supports the hypothesis that FGF signaling promotes PC-1 gene expression by stimulating activity of transcription factors on the PC-1 gene promoter. This finding also suggests the possibility that while FGF signaling promotes the transcriptional activity of Runx2 protein, it may also stimulate a negative feedback loop in which Runx2 mRNA expression is suppressed.

\section{MSX2 STIMULATES PC-1 PROMOTER ACTIVITY IN THE ABSENCE OF RUNX2}

To determine if Runx2 is required for PC-1 promoter activity downstream of Msx2, we examined the PC-1 promoter response to Msx2 and FGF2 in Runx2 deficient COS7 cells. Results demonstrated that while Msx2 increased PC-1 promoter response to FGF2 in these cells, co-expression of Msx2 with Runx2 did not further enhance the FGF2 response (Fig. 4A). Exogenous Runx2 did not diminish expression levels of Msx2 and exogenous Runx2 did not diminish expression levels of Msx2 indicating that the lack of synergy upon co-expression of these factors did not result from diminished expression of either factor (Fig. 4B,C). Because COS7 cells likely lack multiple factors in addition to Runx2 that are normally present in osteoblastic cells, to substantiate these findings, we next examined the PC-1 promoter response to Msx2 and FGF2 in Runx2 deficient calvarial cells [Bae et al., 2007]. 


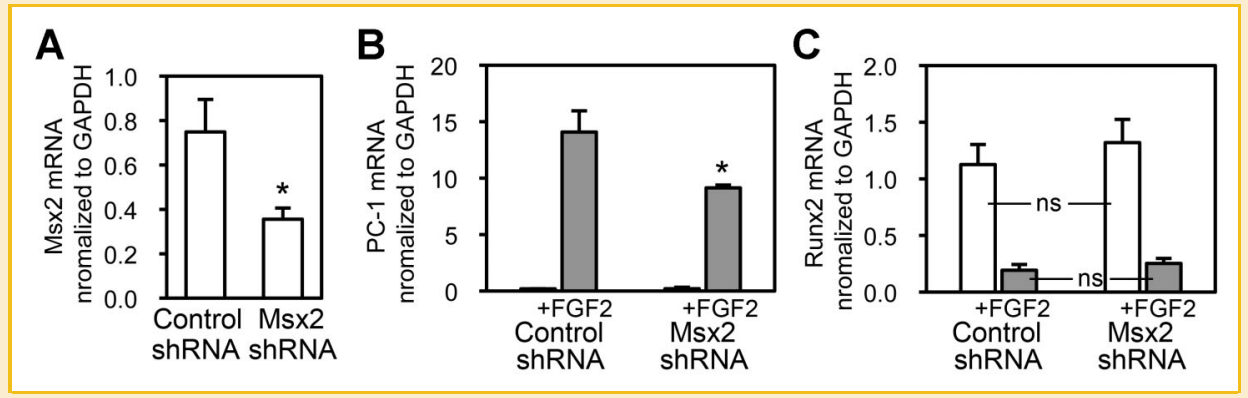

Fig. 3. Maximal Msx2 expression is required for maximal induction of PC-1 gene expression by FGF2. A: Msx2 shRNA suppresses Msx2 expression. Msx2 mRNA levels of MC3T3E1(C4) cells stably expressing non-target or Msx2 specific shRNA are presented as normalized to GAPDH. ${ }^{*} P<0.05$ versus non-target shRNA (control). B: Msx2 suppression diminishes induction of PC-1 gene expression by FGF2. Non-target and Msx2 shRNA expressing cells were treated with FGF2 for $12 \mathrm{~h}$ prior to $\mathrm{mRNA}$ isolation. PC-1 mRNA levels were measured by real-time PCR and PC-1 mRNA levels are presented as normalized to GAPDH ${ }^{*} P<0.05$ versus non-target shRNA (control). $C$ : Msx2 suppression does not alter Runx2 mRNA expression. Runx2 mRNA levels of samples treated similarly to those shown in (B) are presented as normalized to GAPDH. n.s., non-significant difference between indicated groups.

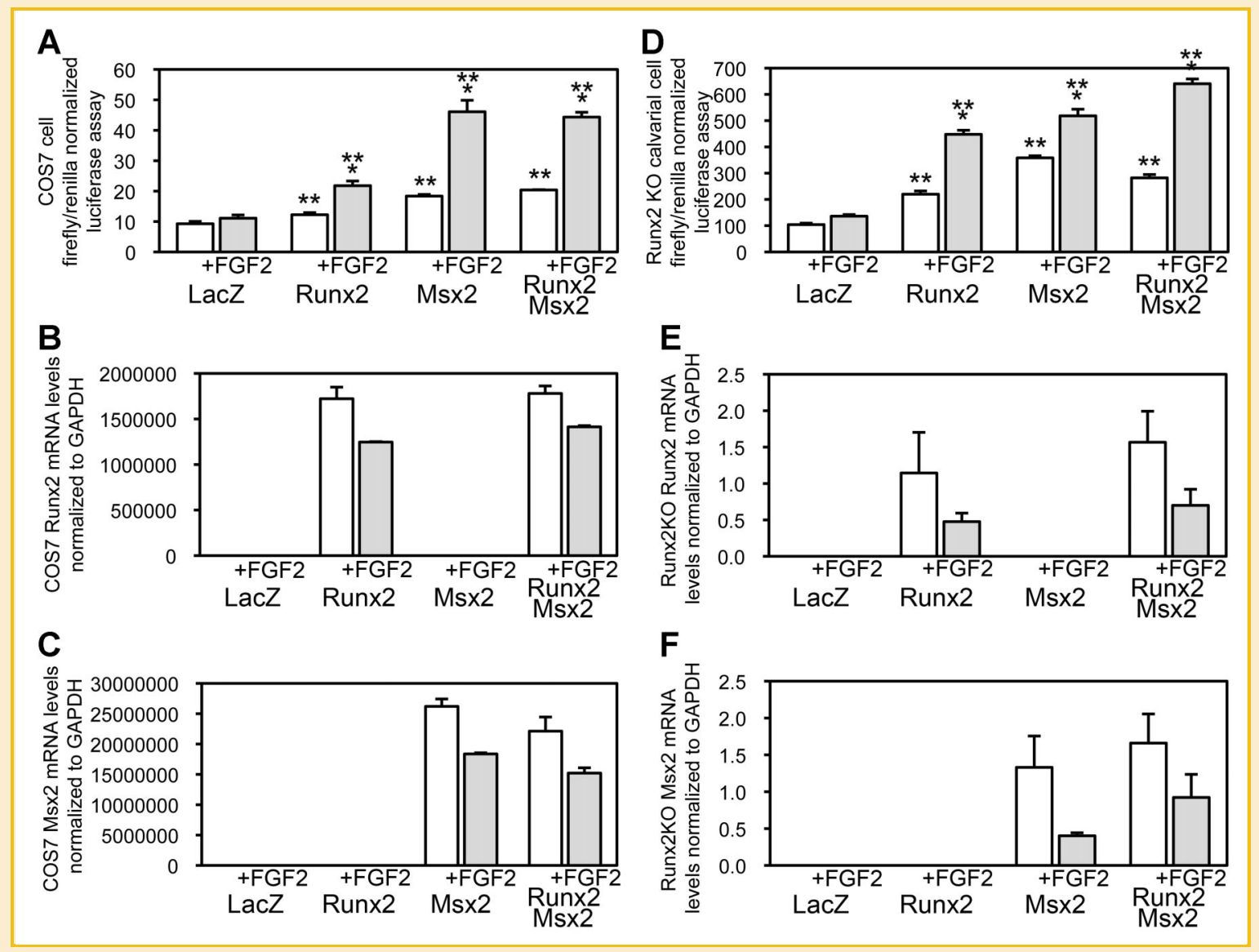

Fig. 4. Runx2 is not required for induction of PC-1 promoter activity by Msx2. A: Msx2 stimulates PC-1 promoter activity in Runx2 deficient COS7 cells. Cells were transfected with PGL4/PC1 firefly, control renilla luciferase constructs, and expression vectors for LacZ, Msx2, Runx2 or Msx2, and Runx2. Cells were then treated with FGF2 and analyzed for luciferase activity. ${ }^{*}<0.05$ versus no tax; ${ }^{* *} P<0.05$ versus LacZ. B,C: Transfection with Runx2 or Msx2 and/or treatment with FGF2 do not increase Runx2 (B) or Msx2 (C) mRNA levels in COS7 cells. Runx2 and Msx2 mRNA levels of samples shown in (A) are presented as normalized to GAPDH. D: Msx2 stimulates PC-1 promoter activity in Runx2 deficient calvarial cells. Cells were transfected with PGL4/PC1 firefly, control renilla luciferase constructs, and expression vectors for LacZ, Msx2, Runx2 or Msx2, and Runx2. Cells were then treated with FGF2 and analyzed for luciferase activity. ${ }^{*} \boldsymbol{P}<0.05$ versus no treatment; ${ }^{* *} P<0.05$ versus LacZ. E,F: Transfection with Runx2 or Msx2 and/ or treatment with FGF2 do not increase Runx2 (E) or Msx2 (F) mRNA levels in Runx2 deficient calvarial cells. Runx2 and Msx2 mRNA levels of samples shown in (B) are presented as normalized to GAPDH. 


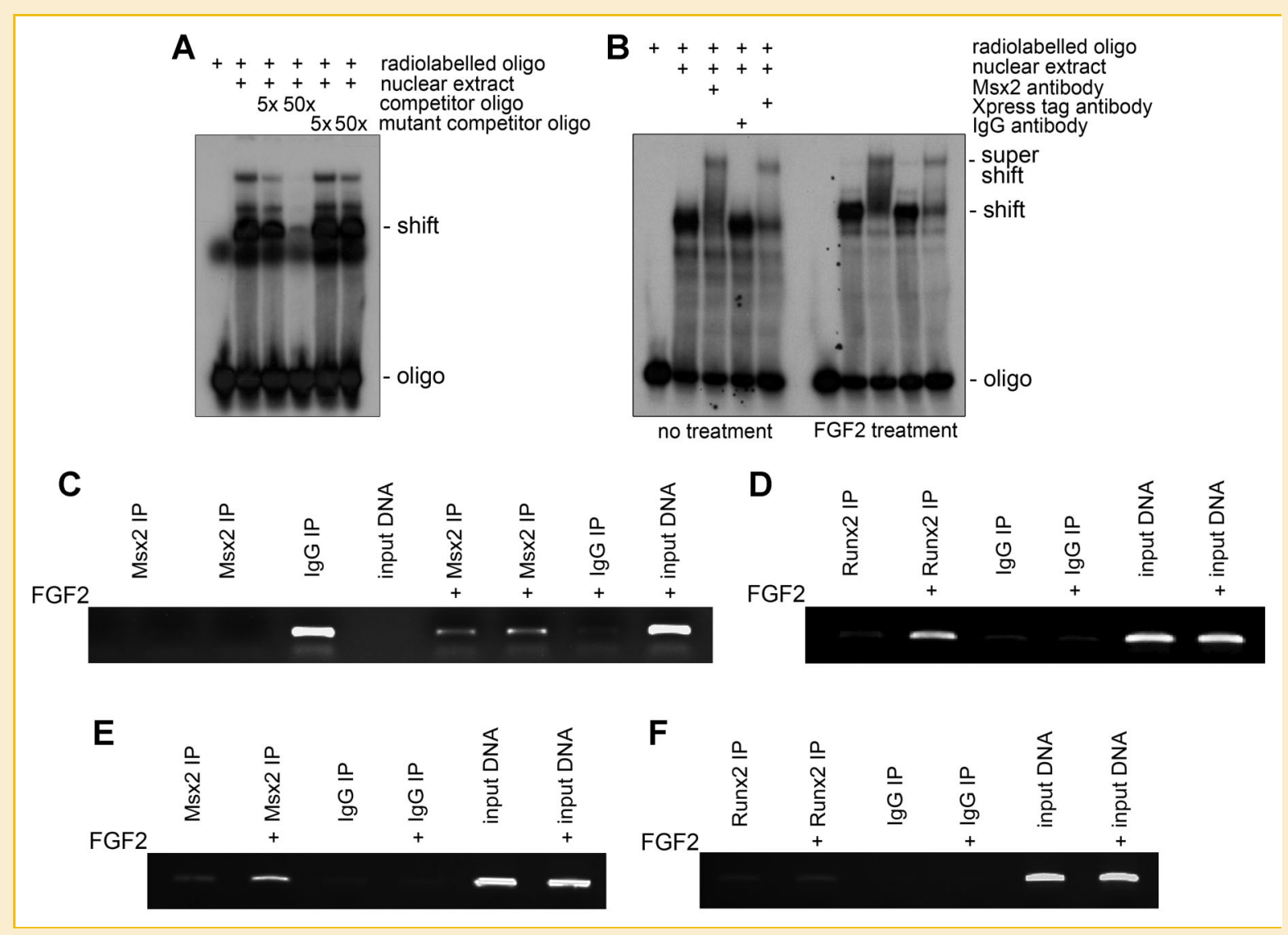

Fig. 5. Msx2 and Runx2 associate with the PC-1 gene promoter. A: Nuclear extract specifically binds to the Msx2 binding site within PC-1 promoter oligonucleotides. MC3T3E1(C4) cells were transfected with Xpress-tagged-Msx2. Isolated nuclear extract was incubated with radiolabeled Msx2-binding-site-containing oligonucleotide or mutant-Msx2-binding-site-containing oligonucleotide (Msx2 cannot bind to this mutant oligonucleotide), and increasing amounts of non-radiolabeled competitor wild-type or competitor mutant oligonucleotide. Samples were analyzed by polyacrylamide gel electrophoresis. B: Msx2 from nuclear extract binds to the Msx2 binding site within PC-1 promoter oligonucleotides. Radiolabeled oligonucleotide was incubated with MC3T3E1(C4) nuclear extract and Msx2, control lgG antibody, or Xpress tag antibody. Samples were analyzed by polyacrylamide gel electrophoresis. C: Msx2 binds to the endogenous PC-1 gene promoter. Untransfected MC3T3E1(C4) cells were cultured with or without FGF2 for $12 \mathrm{~h}$ and cross-linked chromatin was immunoprecipitated with Msx2 or control lgG antibody. PCR was performed using primers generated to detect the Msx2 binding site region found within the PC-1 gene promoter. D: Runx2 binds to the endogenous PC-1 promoter at the Msx2 binding site. Untransfected MC3T3E1(C4) cells were cultured with or without FGF2 for $12 \mathrm{~h}$ and cross-linked chromatin was immunoprecipitated with Runx2 or control lgG antibody. PCR was performed using primers generated to detect the Msx2 binding site region found within the PC-1 gene promoter. This is the same primer set utilized to detect Msx2 binding to the PC-1 gene promoter in (C). E: Msx2 binds to the endogenous PC-1 gene promoter in Runx2 shRNA expressing cells. MC3T3E1(C4) cells transduced with Runx2 shRNA were cultured with or without FGF2 for $12 \mathrm{~h}$ and crosslinked chromatin was immunoprecipitated with Msx2 or control lgG antibody, as described for (C). F: Runx2 does not bind to the endogenous PC-1 promoter at the Msx2 binding site in Msx2 shRNA expressing cells. MC3T3E1(C4) cells transduced with Msx2 shRNA were cultured with or without FGF2 for $12 \mathrm{~h}$ and cross-linked chromatin was immunoprecipitated with Runx2 or control IgG antibody, as described for (D).

Results confirmed that Msx2 stimulates PC-1 promoter activity in the absence of Runx2. Consistent with the COS7 results, coexpression of Msx2 and Runx2 did not lead to a synergistic increase in PC-1 promoter response to FGF2 in the Runx2 deficient calvarial cells (Fig. 4D). Of note, neither FGF2 treatment nor exogenous Runx2 increased expression levels of Msx2, and neither FGF2 treatment nor exogenous Msx2 increased expression levels of Runx2 in COS7 cells (Fig. 4E,F). Together these findings indicate that Msx2 can function as a transcriptional activator of the PC-1 gene independently of Runx2. Because Runx2 deficient calvarial cells likely lack osteoblastic factors in addition to Runx2, these findings also suggest that the synergistic promoter response to FGF2 seen in MC3T3E1(C4) and C310T1/2 cells upon coexpression of Msx2 with Runx2 may require the presence of an additional factor that is absent from the COS7 and Runx2 deficient calvarial mesenchymal cells.

\section{MSX2 AND RUNX2 ASSOCIATE WITH THE PC-1 GENE PROMOTER}

Electrophoretic mobility shift assays were undertaken to establish that Msx2 present in nuclear extracts of pre-osteoblasts binds to the potential Msx2 binding site within the PC-1 gene promoter. Incubation of double stranded oligonucleotide containing the putative Msx2 binding site with nuclear extract purified from MC3T3E1(C4) cells resulted in a significant shift in migration of the oligonucleotide. Competition with excessive amounts of nonradioactive oligonucleotide successfully blocked the shift in oligonucleotide migration. In contrast, oligonucleotides containing point mutations in the core Msx2 binding site were unable to 


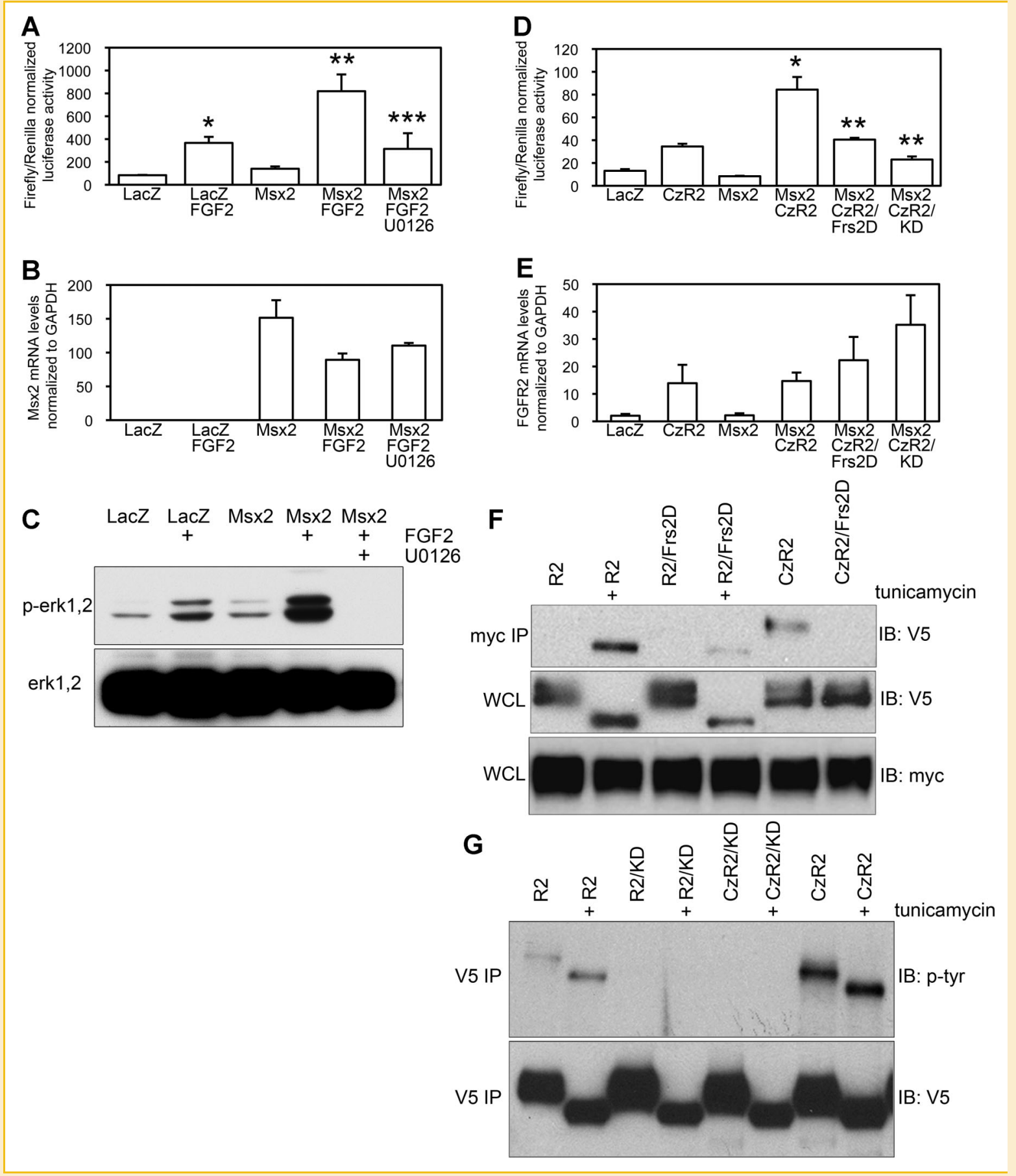

Fig. 6. FGF2 promotes Msx2 transcriptional activity through the Frs2 mediated MAPK signaling pathway. A: MAPK inhibitor U0126 abrogates FGF2 stimulated Msx2 transcriptional activity. MC3T3E1(C4) cells were transfected with expression constructs for LacZ or Msx2, pre-treated with $10 \mu M$ U0126 for $1 / 2 \mathrm{~h}$ then treated with FGF2 for $24 \mathrm{~h}$ prior to cell lysis for luciferase activity. ${ }^{*} \boldsymbol{P}<0.05$ versus LacZ/no FGF2; ${ }^{* *} \boldsymbol{P}<0.05$ versus LacZ/+FGF2; ${ }^{* * *} \boldsymbol{P}<0.05$ versus Msx2/+FGF2. B: U0126 does not diminish Msx2 expression levels. Msx2 mRNA levels of samples treated similarly to those shown in A are presented as normalized to GAPDH. C: U0126 inhibits phosphorylation of MAPK. MC3T3E1(C4) cells were transfected with LacZ or Msx2 and treated with U0126 as described in (A). Cell lysate was immunoblotted for phosphorylated erk1,2 (MAPK) and reprobed for total erk1,2 protein. D: FGF signaling stimulates Msx2 transcriptional activity through Frs2. MC3T3E1(C4) cells were transfected with LacZ or Msx2, and Crouzon syndrome mutant, auto-active variants of FGFR2 (CzR2) that are specifically deficient in signaling through Frs2 (CzR2/frs2D), or are tyrosine kinase domain inactive (CzR2/KD), prior to analysis by luciferase assay. ${ }^{*} P<0.05$ versus Msx2. ${ }^{* *} P<0.05$ versus Msx2/CzR2. E: Incorporation of Frs2 binding site and kinase domain mutations does not diminish FGFR2 expression levels. FGFR2 mRNA levels of samples treated similarly to those shown in (D) are presented as normalized to GAPDH. F: Frs2 binding site mutation in FGFR2 prevents binding to Frs2. COS7 cells were transfected with V5-labeled wild-type FGFR2 (R2) or auto-active FGFR2 (CzR2) constructs and myc-labeled Frs2, then treated with/ without $10 \mu \mathrm{M}$ tunicamycin for $24 \mathrm{~h}$ prior to immunoprecipitation. Tunicamycin inhibits FGFR glycosylation, causing ligand independent receptor activation. Myc-labeled-Frs2 immunoprecipitate was immunoblotted for V5-labeled-FGFR2. Control panels show whole cell lysate immunoblotted with anti-V5 antibody or anti-myc antibody. G: Kinase domain mutation in FGFR2 prevents receptor activation. COS7 cells were transfected with V5-labeled wild-type FGFR2 (R2) or auto-active FGFR2 constructs (CZR2) and treated with/without $10 \mu \mathrm{M}$ tunicamycin for $24 \mathrm{~h}$ prior to immunoprecipitation. Tunicamycin inhibits FGFR glycosylation, causing ligand independent receptor activation. V5-labeledFGFR2 immunoprecipitate was immunoblotted for anti-phosphotyrosine. Control panel shows whole cell lysate immunoblotted with anti-V5 antibody. 
compete with bound species (Fig. 5A). Supershift assays using two different anti-Msx2 antibodies confirmed that the shifted complex contained Msx2 (Fig. 5B). These results indicate that Msx2 binds to the PC-1 gene promoter in vitro. Significantly, migration of bound complexes from FGF2 treated cells was slower than that of untreated cells, indicating that the Msx2 binding complex from FGF2 treated nuclear extract may contain additional factors.

Chromatin immunoprecipitation (ChIP) assays confirmed that Msx2 binds to the endogenous PC-1 gene promoter in intact cells. Msx2 antibody specific ChIP yielded stronger positive signals in FGF2 treated than in untreated MC3T3E1(C4) cells (Fig. 5C). This indicates that Msx2 is recruited to the PC-1 gene promoter in FGF2 treated calvarial pre-osteoblastic cells. To determine if Runx2 and Msx2 interact at the Msx2 binding site, we next performed Runx2 antibody specific ChIP followed by PCR for the Msx2 binding site. Results demonstrate that Runx2 is also recruited to the Msx2 binding site upon exposure to FGF2 (Fig. 5D). Of note, Msx2 antibody specific ChIP followed by PCR for Runx2 bindings sites indicate that Msx2 is not associated with chromatin at or near the Runx2 binding sites in FGF treated cells (data not shown). To determine if Runx2 is required for the binding of Msx2 to the endogenous PC-1 gene promoter, we performed Msx2 ChIP in cells expressing Runx2 shRNA. These cells express significantly diminished Runx2 levels (supplemental data). Results show that Msx2 is still recruited to the Msx2 binding site of the PC-1 gene promoter upon FGF2 treatment (Fig. 5E). Next, to determine if Msx2 is required for the recruitment of Runx2 to the Msx2 binding site within the endogenous PC-1 gene promoter, we performed Runx2 ChIP in cells expressing Msx2 shRNA (show diminished Msx2 expression). Results demonstrate that Runx2 does not bind to the $\mathrm{PC}-1$ gene promoter at the Msx2 binding site in cells that express Msx2 shRNA (Fig. 5F). Together these results indicate that Msx2 is required for the binding of Runx2, but Runx2 is not required for the binding of Msx 2 to the endogenous PC-1 gene promoter at the Msx2 binding site in FGF2 treated cells.

\section{FRS2 AND MAPK SIGNALING PROMOTES MSX2 TRANSCRIPTIONAL ACTIVITY}

To establish the signaling mechanism by which FGF2 promotes Msx2 transcriptional activity on the $\mathrm{PC}-1$ gene promoter, we investigated PC-1 promoter response to FGF2 and Msx2 upon treatment with the MAPK (erk1,2) specific inhibitor U0126. Results indicate that U0126 treatment abrogated FGF2 stimulated Msx2 transcriptional activity in MC3T3E1(C4) cells (Fig. 6A). Importantly, treatment of cells with U0126 and FGF2 did not diminish Msx2 expression levels compared to treatment of cells with FGF2 alone, indicating that the loss of Msx2 transcriptional activity upon U0126 treatment was not due to diminished Msx2 expression (Fig. 6B). Additionally, immunoblot of whole cell lysate from similarly treated cells confirmed that U0126 abrogates the MAPK phosphorylation seen upon FGF2 treatment in our experimental design (Fig. 6C).

Because MAPK activity is stimulated upon recruitment of Frs2 to the FGF receptor, we next utilized a series of auto-active FGFR2 constructs to determine if FGF signaling stimulates Msx2 transcriptional activity via Frs2. These constructs contain a $\mathrm{C} 278 \mathrm{~F}$ mutation that results in constitutive receptor signaling and craniosynostosis [Oldridge et al., 1995; Hatch et al., 2006]. FGFR2 ${ }^{\mathrm{C} 278 \mathrm{~F}}$ (CzR2) exhibits ligand independent auto-phosphorylation and activity. FGFR2 ${ }^{\mathrm{C} 278 \mathrm{~F}}$ containing an additional mutation in the tyrosine kinase domain is kinase activity dead (Cz/KD), so cannot signal. FGFR2 ${ }^{\mathrm{C} 278 \mathrm{~F}}$ containing an additional mutation that specifically eliminates the Frs2 binding site (CzR2/Frs2D) can signal through PLC $\gamma$ but not through Frs2, and therefore cannot signal through MAPK.

PC-1 promoter luciferase assays utilizing these FGF receptor constructs demonstrated that FGFR2 ${ }^{\mathrm{C} 278 \mathrm{~F}}$ (CzR2) stimulates Msx2 transcriptional activity but that FGFR2 ${ }^{\mathrm{C} 278 \mathrm{~F}}$ that is deficient in the ability to bind Frs2 (CzR2/Frs2D) and FGFR2 ${ }^{\mathrm{C} 278 \mathrm{~F}}$ that cannot autophosphorylate $(\mathrm{CzR} 2 / \mathrm{KD})$ do not stimulate Msx2 transcriptional activity on the PC-1 gene promoter (Fig. 6D). Importantly, real time PCR for FGFR2 demonstrates that the differences in Msx2 transcriptional activity upon co-expression with the various receptor constructs is not likely due to differences in FGF receptor expression (Fig. 6E). Additional control experiments confirm that CzR2/Frs2D does not bind Frs2 upon receptor activation (Fig. 6F) and that $\mathrm{CzR} 2 / \mathrm{KD}$ does not auto-phosphorylate upon receptor activation (Fig. 6G). Interpretation of these control experiments requires the knowledge that tunicamycin inhibits FGF receptor glycosylation leading to ligand independent receptor dimerization and signaling [Hatch et al., 2006]. Taken together our results indicate that auto-active FGFR2 (FGFR2 $\left.{ }^{\mathrm{C} 278 \mathrm{~F}} / \mathrm{CzR} 2\right)$ stimulates Msx2 transcriptional activity and that this requires receptor autophosphorylation and the recruitment of Frs2 to FGFR2. Because Frs2 stimulates MAPK signaling downstream of activated FGF receptors, these results support our hypothesis that FGF signaling stimulates Msx2 transcriptional activity via an Frs2/MAPK pathway.

\section{DISCUSSION}

We previously showed that FGF2 induces expression of the pyrophosphate-generating enzyme $\mathrm{PC}-1$ in a pre-osteoblast cell type specific and Runx2 dependent manner [Hatch et al., 2009]. Because PC-1 activity is an established regulator of hard and soft tissue mineralization, because activating mutations in both FGF receptors and Msx2 results in premature fusion of cranial bones (craniosynostosis), and because Msx2 can specifically regulate Runx2 transcriptional activity downstream of FGF2 [Shirakabe et al., 2001; Sierra et al., 2004], here we investigated Msx2 as an additional mediator of PC-1 gene expression in calvarial preosteoblasts. We show that mutation of a conserved Msx2 binding site in the proximal PC-1 gene promoter, which prevents Msx2 from binding to the promoter, results in diminished promoter responsiveness to FGF2. Additionally, we show that Msx2 up-regulates PC1 promoter activity and $\mathrm{PC}-1$ gene expression in calvarial preosteoblasts upon FGF2 treatment, and that suppression of Msx2 diminishes the induction of PC-1 gene expression by FGF2. These results indicate that Msx2 acts as a transcriptional enhancer of the PC-1 gene downstream of FGF2. Notably, co-expression of Runx2 with Msx2 had a synergistic effect on PC-1 promoter activity in the MC3T3E1(C4) calvarial pre-osteoblastic cell line, indicating that 
Runx2 and Msx2 may function cooperatively to induce PC-1 expression in calvarial pre-osteoblasts.

Because we previously showed that FGF2 induced PC-1 expression was mediated by Runx2 and because previous reports have demonstrated that Msx2 mediates osteoblastic gene expression by interacting with Runx2, we next investigated the ability of Msx2 to induce PC-1 expression in the absence of Runx2. Here we find that Msx2 activates PC-1 promoter activity in Runx2 deficient COS7 cells and in calvarial cells of Runx2 deficient mice. Notably though, the combination of Runx2 with Msx2 did not lead to a synergistic increase in promoter activity in these cells. Together these results indicate that Msx2 does not require Runx2 to activate transcription of the PC-1 gene promoter but that Runx2 may be required for maximal induction of PC-1 gene expression downstream of FGF2 and Msx2. These results may also indicate that factors in addition to Runx2 and Msx2 are required for the cooperative induction of PC-1 expression in pre-osteoblastic cells.

Msx2 regulates gene transcription in osteoblastic cells by binding to transcription factors such as Runx2 and Dlx5, or by competing with these factors for promoter DNA binding sites [Newberry et al., 1997; Shirakabe et al., 2001; Willis et al., 2002; Sierra et al., 2004]. Through electrophoretic mobility shift (EMSA), and chromatin immunoprecipitation (ChIP) assays, here we confirm that Msx2 binds to the identified Msx2 binding site within the PC-1 gene promoter. Significantly, EMSA studies showed slower migration of promoter bound complexes from cells that had been treated with FGF2 than from untreated cells, indicating that additional factors are recruited to this binding site upon FGF2 stimulation. ChIP results demonstrated that both Msx2 and Runx2 are actively recruited to the Msx 2 binding site of the endogenous PC-1 gene promoter upon FGF2 treatment in intact cells. ChIP for Runx2 in Msx2 shRNA expressing cells revealed significantly diminished recruitment of Runx2 to the Msx2 binding site but ChIP for Msx2 in Runx2 shRNA expressing cells did not show diminish recruitment of Msx2 to the Msx2 binding site in FGF2 treated cells. These findings again support the idea that Runx2 and Msx2 function together to induce PC-1 gene expression downstream of FGF2. Msx2 appears to function as a mediator for the recruitment of Runx2 to the Msx2 binding site in the PC-1 gene promoter. Further studies are required determine if FGF signaling leads to additional co-factor recruitment and binding to the identified Msx2 binding site.

It is worthy to note here that transfection with Msx2 tended to yield suppression of endogenous Runx2 expression in preosteoblastic C3H10T1/2 and MC3T3E1(C4) cells (Fig. 2C,F). This is consistent with the previously reported finding that Msx2 and Runx2 are expressed at different times during osteoblast differentiation and could suggest that Msx2 acts to displace Runx2 on the PC-1 gene promoter [Hassan et al., 2004]. We consider this latter contention to be unlikely, because both Msx2 and Runx2 are recruited to the endogenous Msx2 binding site in FGF2 treated cells (Fig. 5C,D), because Msx2 does not bind to the Runx2 binding sites in the PC-1 gene promoter, even upon FGF2 stimulation (data not shown) and because Msx2 mediates the recruitment of Runx2 to the Msx2 binding site within the PC-1 gene promoter (Fig. 5F). Dissimilar to many other genes regulated by Msx2 and Runx2, these transcription factors appear to be functioning cooperatively in the induction of PC-1 gene expression downstream of FGF signaling in osteoblastic precursor cells.

That FGF2 promotes recruitment of Msx2 to the PC-1 gene promoter without increasing Msx2 expression levels could indicate that FGF signaling promotes Msx2 activity though a posttranslational mechanism. Previous studies indicate that FGF2 stimulates Runx2 transcriptional activity by PKC or MAPK mediated serine phosphorylation [Xiao et al., 2002; Franceschi et al., 2003; Kim et al., 2003, 2006]. With the use of inhibitors and signal cascade deficient FGF receptor constructs, here we show that FGF2 stimulates Msx2 transcriptional activity through an Frs2 mediated MAPK signaling pathway (Fig. 7). Bioinformatic analysis of the murine Msx2 protein reveals six potential serines and one potential threonine site with high prediction scores for MAPK phosphorylation [Group-based Prediction System, Version 2.1; Xue et al., 2008]. Future studies will be required to determine if FGF2 stimulates Msx2 activity through MAPK mediated phosphorylation of specific serine and/or threonine residues.

The finding that Msx2 enhances transcription of PC-1 downstream of FGF mediated MAPK signaling is significant. To our knowledge this is the first study to show Msx2 functioning as a transcriptional enhancer downstream of FGF2 in calvarial preosteoblasts. We also show that Msx2 functions cooperatively with Runx2 on the PC-1 gene promoter. Understanding how Msx2 can enhance Runx2 transcriptional activity downstream of FGF signaling in some cases (e.g., PC-1 gene expression), and inhibit it in others [e.g., osteocalcin gene expression, as initially reported by Newberry et al., 1997], should increase our ability to control activity of these factors for the development of biologic therapeutics in guided bony tissue regeneration.

Our results may also provide new insights into the molecular pathogenesis of craniosynostosis. The finding that Msx2 enhances the effects of FGF signaling on expression of PC-1 in preosteoblastic cells supports the idea that FGF receptor signaling and Msx2 activity influence craniofacial osteogenesis via the same molecular mechanism. As previously noted, activating mutations in FGF receptors and Msx2 are both associated with aberrant craniofacial development in the form of craniosynostosis [Jabs et al., 1993; Liu et al., 1995; Reardon et al., 1994], but the molecular pathogenesis by which craniosynostosis develops downstream of these mutations remains unknown. Notably, while craniosynostosis has traditionally been described as a disease of increased bone mineralization, this may not be the most accurate description of the condition. A close look at the FGFR-associated craniosynostosis phenotype demonstrates diminished calvarial and vertebral bone mineralization with increased calcification of associated soft tissues. In depth radiographic analyses of patients with syndromic craniosynostosis reveals a high percentage of patients to exhibit joint stiffness, ligament calcifications, and vertebral fusions [Kreiborg, 1981; Cohen and Kreiborg, 1993, 1996]. The FGFR2 2250 W mouse model of Apert syndrome shows craniosynostosis with decreased cranial bone formation and thickness [Zhou et al., 2000; Chen et al., 2003]. The FGFR2 ${ }^{\mathrm{C} 342 \mathrm{Y}}$ mouse model of Crouzon syndrome shows craniosynostosis with vertebral joint fusions and diminished vertebral body ossification [Eswarakumar et al., 2004] Together these data indicate that FGFR-associated craniosynostosis 


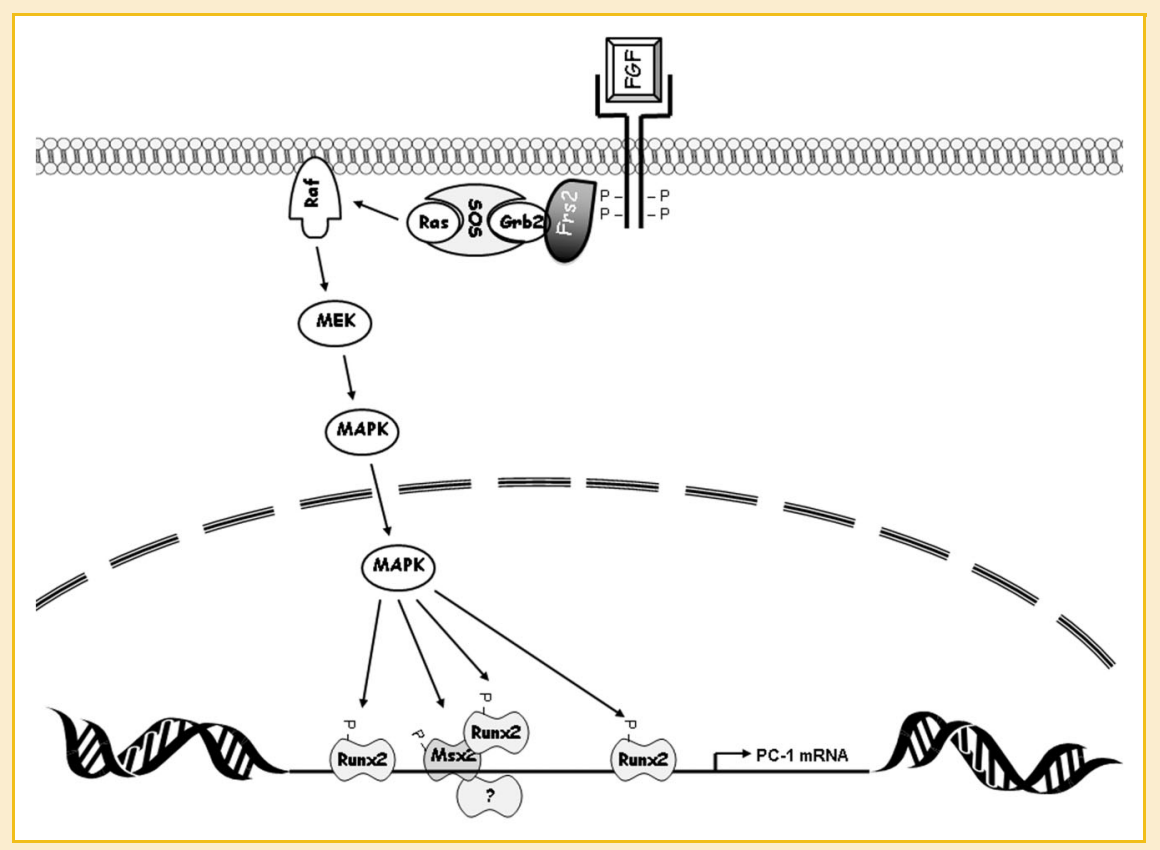

Fig. 7. Schematic diagram of Frs2/MAPK mediated FGF signaling effects on PC-1 promoter activity. FGF receptor activity is stimulated by high affinity binding to FGF ligand. Receptor activation results in autophosphorylation and recruitment of the docking protein Frs2. Frs2 is then itself phosphorylated, leading to the binding and activation of adaptor proteins Grb2, Shp2, and Sos1. This complex activates membrane bound Raf, which then activates MEK. MEK, in turn, activates MAPK by phosphorylation (Erk-1,2). Upon phosphorylation, MAPK translocates into the nucleus where it stimulates the transcriptional activity of Runx2 and Msx2, likely via phosphorylation. Activated Runx2 binds to the PC-1 gene promoter via conserved Runx2 binding sites at positions $-2554,-2500,-810$, and -312 [Hatch et al., 2009]. Upon activation, Msx2 binds to the PC-1 gene promoter via a conserved Msx2 binding site located at position -1892. Runx2 also binds to chromatin at or near the Msx2 binding site, likely via a transcription factor complex involving Msx2. Binding of both Runx2 and Msx2 is required for maximal induction of PC-1 promoter activity and expression of PC-1 mRNA. Future studies are required to determine if MAPK and/or Msx2 activity promote the recruitment of additional co-factors to the PC-1 gene promoter.

is a disease involving diminished bone mineralization of calvaria and vertebrae, with aberrant calcification of associated soft tissues, including the cranial sutures and vertebral ligaments. If this is the case, it is critical to recognize that increased levels of extracellular pyrophosphate can result in the pathologic calcification of nonbone tissues, as has been evidenced in human diseases involving excessive PC-1 activity [Terkeltaub et al., 1994; Terkeltaub, 2001; Johnson et al., 2001a,b; Johnson and Terkeltaub, 2005].

Our results suggest that mutant FGFR signaling and/or Msx2 activity may lead to increased calvarial cellular expression of PC- 1 . This in turn would yield a phenotype of excessive extracellular pyrophosphate with the potential for pathologic matrix calcification of non-bony tissues, including the developing cranial suture. In support of this idea is the fact that craniosynostosis is also associated with inactivating mutations in TNAP [Wenkert et al., 2009]. TNAP is an established mediator of tissue mineralization, but it is unknown how diminished TNAP activity leads to craniosynostosis. Because TNAP hydrolyzes PC-1 generated pyrophosphate to phosphate, patients with inactivating mutations in TNAP exhibit hyperpyrophosphatemia. It is unknown if TNAP-associated craniosynostosis is mediated by the high pyrophosphate levels seen in these patients.

While the idea that FGF signaling and Msx2 both act to promote precursor cell osteoblastic differentiation is not a novel concept, this is the first report of a direct link between Msx2 and FGF signaling in promotion of a calvarial osteoblast precursor cell phenotype. Our results suggest that FGF's and Msx2 function in the same pathway to promote a pre-osteoblastic cell phenotype that includes the induction of PC-1 gene expression. Future studies will be needed to establish the significance of this phenomenon in the overall effects of FGF signaling and Msx2 activity on craniofacial osteogenesis and craniosynostosis.

\section{ACKNOWLEDGMENTS}

We are sincerely grateful to Dr. Renny Franceschi and Dr. Chunxi Ge for providing intellectual and practical support of this project.

\section{REFERENCES}

Anderson HC, Sipe JB, Hessle L, Dhamyamraju R, Atti E, Camacho NP, Millan JL. 2004. Sustained osteomalacia of long bones despite major improvement in other hypophosphatasia-related mineral deficits in tissue nonspecific alkaline phosphatase/nucleotide pyrophosphatase phosphodiesterase 1 double-deficient mice. Am J Pathol 164:841-847.

Anderson HC, Harmey D, Camacho NP, Garimella R, Sipe JB, Tague S, Bi X, Johnson K, Terkeltaub R, Millan JL. 2005. Sustained osteomalacia of long bones despite major improvement in other hypophosphatasia-related mineral deficits in tissue nonspecific alkaline phosphatase/nucleotide pyrophosphatase phosphodiesterase 1 double-deficient mice. Am J Pathol 166: 1711-1720. 
Bae J, Gutierrez S, Narla R, Pratap J, Devados R, van Wijnen AJ, Stein JL, Stein GS, Lian JB, Javed A. 2007. Reconstitution of Runx2/Cbfa1-null cells identifies a requirement for BMP2 signaling through a Runx2 functional domain during osteoblast differentiation. J Cell Biochem 100:434-449.

Barnes GL, Javed A, Waller SA, Kamal MH, Hebert KE, Hassan MQ, Bellahcene van Wijnen AJ, Young MF, Lian JB, Stein GS, Gerstenfeld LC. 2003. Osteoblast-related transcription factors Runx2 (Cbfa1/AML3) and MSX2 mediate the expression of bone sialoprotein in human metastatic breast cancer cells. Cancer Res 63:2631-2637.

Berra E, Díaz-Meco MT, Lozano J, Frutos S, Municio MM, Sánchez P, Sanz L, Moscat J. 1995. Evidence for a role of MEK and MAPK during signal transduction by protein kinase C zeta. EMBO J 14:6157-6163.

Chen L, Li D, Li C, Engel A, Deng CX. 2003. A Ser252Trp substitution in mouse fibroblast growth factor receptor 2 (Fgfr2) results in craniosynostosis. Bone 33:169-178.

Cohen MM, Kreiborg S. 1993. Skeletal abnormalities in the Apert syndrome. Am J Med Genet 47:624-632.

Cohen MM, Kreiborg S. 1996. A clinical study of the craniofacial features in Apert syndrome. Int J Oral Maxillofac Surg 25:45-53.

Dodig M, Kronenberg MS, Bedalov A, Kream BE, Gronowicz G, Clark SH, Mack K, Liu Y, Maxson R, Pan ZZ, Upholt WB, Rowe DW, Lichtler AC. 1996. Identification of a TAAT-containing motif required for high level expression of the COL1A1 promoter in differentiated osteoblasts of transgenic mice. J Biol Chem 271:16422-16429.

Eswarakumar VP, Horowitz MC, Locklin R, Morriss-Kay GM, Lonai P. 2004. A gain-of-function mutation of Fgfr2c demonstrates the roles of this receptor variant in osteogenesis. Proc Natl Acad Sci 101:12555-12560.

Fleisch H, Straumann F, Schen R, Bisaz S, Allgower M. 1966. Effect of pyrophosphate on hydroxyapatite and its implications in calcium homeostasis. Am J Physiol 211:821-825.

Franceschi RT, Xiao G, Jiang D, Gopalakrishnan R, Yang S, Reith E. 2003. Multiple signaling pathways converge on the Cbfa1/Runx2 transcription factor to regulate osteoblast differentiation. Connect Tiss Res 44 (Suppl. 1): 109-116.

Ge C, Xiao G, Jiang D, Yang Q, Hatch NE, Roca H, Franceschi RT. 2009. Identification and functional characterization of ERK/MAPK phosphorylation sites in the Runx2 transcription factor. J Biol Chem 284:32533-32543.

Hassan MQ, Javed A, Morasso MI, Karlin J, Montecino M, van Wijnen AJ, Stein GS, Stein JL, Lian JB. 2004. Dlx3 transcriptional regulation of osteoblast differentiation: Temporal recruitment of Msx2, Dlx3, and Dlx5 homeodomain proteins to chromatin of the osteocalcin gene. Mol Cell Biol 24:9248-9261.

Hassan MQ, Tare RS, Lee SH, Mandeville M, Morasso MI, Javed Z, van Wijnen AJ, Stein JL, Stein GS, Lian JB. 2006. BMP2 commitment to the osteogenic lineage involves activation of Runx2 by DLX3 and a homeodomain transcriptional network. J Biol Chem 281:40515-40526.

Hatch N, Nocito C, Swanson E, Bothwell MA, Somerman MJ. 2005. FGF2 alters expression of the pyrophosphate/phosphate regulating proteins, PC-1, ANK and TNAP, in the calvarial osteoblastic cell line, MC3T3E1(C4). Conn Tiss Res 46:184-192.

Hatch NE, Hudson M, Seto ML, Cunningham ML, Bothwell M. 2006. Intracellular retention, degradation, and signaling of glycosylation-deficient FGFR2 and craniosynostosis syndrome-associated FGFR2C278F. J Biol Chem 281:27292-27305.

Hatch NE, Li Y, Franceschi RT. 2009. FGF2 stimulation of the pyrophosphategenerating enzyme, PC-1, in pre-osteoblast cells is mediated by Runx2. J Bone Miner Res 24:652-662.

Hessle L, Johnson KA, Anderson HC, Narisawa S, Sali A, Goding JW, Terkeltaub R, Millan JL. 2002. Tissue-nonspecific alkaline phosphatase and plasma cell membrane glycoprotein-1 are central antagonistic regulators of bone mineralization. Proc Natl Acad Sci 99:9445-9449.
Jabs EW, Müller U, Li X, Ma L, Luo W, Haworth IS, Klisak I, Sparkes R, Warman ML, Mulliken JB, Snead ML, Maxson R. 1993. A mutation in the homeodomain of the human MSX2 gene in a family affected with autosomal dominant craniosynostosis. Cell 75:443-450.

Johnson K, Terkeltaub R. 2005. Inorganic pyrophosphate (PPI) in pathologic calcification of articular cartilage. Front Biosci 10:988-997.

Johnson K, Moffa A, Chen Y, Prizker K, Goding J, Terkeltaub R. 1999. Matrix vesicle plasma cell membrane glycoprotein-1 regulates mineralization by murine osteoblastic MC3T3 cells. J Bone Miner Res 14:883-892.

Johnson KA, Hessle L, Vaingankar S, Wennerg C, Mauro S, Narisawa S, Goding JW, Sano K, Millan JL, Terkeltaub R. 2000. Osteoblast tissue-nonspecific alkaline phosphatase antagonizes and regulates PC-1. Am J Physiol Int Comp Physiol 279:1365-1377.

Johnson K, Pritzker K, Goding J, Terkeltaub R. 2001a. The nucleoside triphosphate pyrophosphohydrolase isozyme PC-1 directly promotes cartilage calcification through chondrocyte apoptosis and increased calcium precipitation by mineralizing vesicles. J Rheumatol 28:2681-2691.

Johnson K, Hashimoto S, Lotz M, Pritzker K, Goding J, Terkeltaub R. 2001b. Up-regulated expression of the phosphodiesterase nucleotide pyrophosphatase family member PC-1 is a marker and pathogenic factor for knee meniscal cartilage matrix calcification. Arthritis Rheum 44:1071-1081.

Johnson K, Goding J, Van Etten D, Sali A, Hu S, Farley D, Krug H, Hessle L, Millan JL, Terkeltaub R. 2003. Linked deficiencies in extracellular PP(i)and osteopontin mediate pathologic calcification associated with defective PC-1 and ANK expression. J Bone Miner Res 18:994-1004.

Kim H, Kim J, Bae S, Choi J, Kim H, Ryoo H. 2003. The protein kinase C pathway plays a central role in the fibroblast growth factor-stimulated expression and transactivation activity of Runx2. J Biol Chem 278:319326.

Kim YJ, Lee MH, Wozney JM, Cho JY, Ryoo HM. 2004. Bone morphogenetic protein-2-induced alkaline phosphatase expression is stimulated by Dlx5 and repressed by Msx2. J Biol Chem 279:50773-50780.

Kim B, Kim H, Park H, Kim Y, Yoon W, Lee S, Ryoo H, Cho J. 2006. Runx2 phosphorylation induced by fibroblast growth factor-2/protein kinase $\mathrm{C}$ pathways. Proteomics 6:1166-1174.

Kreiborg S. 1981. Crouzon syndrome. A clinical and roentgencephalometric study. Scan J Plast Reconstr Surg Suppl 18:1-198.

Lim YP, Low BC, Lim J, Wong ES, Guy GR. 1999. Association of atypical protein kinase $\mathrm{C}$ isotypes with the docker protein FRS2 in fibroblast growth factor signaling. J Biol Chem 274:19025-19034.

Liu YH, Kundu R, Wu L, Luo W, Ignelzi MA, Snead ML, Maxson RE. 1995. Premature suture closure and ectopic cranial bone in mice expressing Msx2 transgenes in the developing skull. Proc Natl Acad Sci 92:6137-6141.

Mohammadi M, Dikic I, Sorokin A, Burgess WH, Jaye M, Schlessinger J. 1996. Identification of six novel autophosphorylation sites on fibroblast growth factor receptor 1 and elucidation of their importance in receptor activation and signal transduction. Mol Cell Biol 16:977-989.

Murshed M, Harmey D, Millán JL, McKee MD, Karsenty G. 2005. Unique coexpression in osteoblasts of broadly expressed genes accounts for the spatial restriction of ECM mineralization to bone. Genes Dev 19:10931104.

Newberry EP, Boudreaux JM, Towler DA. 1997. Stimulus-selective inhibition of rat osteocalcin promoter induction and protein-DNA interactions by the homeodomain repressor Msx2. J Biol Chem 272:29607-29613.

Oldridge M, Wilkie A0, Slaney SF, Poole MD, Pulleyn LJ, Rutland P, Hockley AD, Wake MJ, Goldin JH, Winter RM. 1995. Mutations in the third immunoglobulin domain of the fibroblast growth factor receptor-2 gene in Crouzon syndrome. Hum Mol Genet 4:1077-1082.

Phimphilai M, Zhao Z, Boules H, Roca H, Franceschi RT. 2006. BMP signaling is required for RUNX2-dependent induction of the osteoblast phenotype. J Bone Miner Res 21(4): 637-646. 
Reardon W, Winter RM, Rutland P, Pulleyn LJ, Jones BM, Malcolm S. 1994. Mutations in the fibroblast growth factor receptor 2 gene cause Crouzon syndrome. Nat Genet 8:98-103.

Register TC, Wuthier RE. 1985. Effect of pyrophosphate and two diphosphonates on $45 \mathrm{Ca}$ and $32 \mathrm{Pi}$ uptake and mineralization by matrix vesicleenriched fractions and by hydroxyapatite. Bone 6:307-312.

Ridyard MS, Robbins SM. 2003. Fibroblast growth factor-2-induced signaling through lipid raft-associated fibroblast growth factor receptor substrate 2 (FRS2). J Biol Chem 278:13803-13809.

Roca H, Phimphilai M, Gopalakrishnan R, Xiao G, Franceschi RT. 2005. Cooperative interactions between RUNX2 and homeodomain protein-binding sites are critical for the osteoblast-specific expression of the bone sialoprotein gene. J Biol Chem 280:30845-30855.

Shirakabe K, Terasawa K, Miyama K, Shibuya H, Nishida E. 2001. Regulation of the activity of the transcription factor Runx2 by two homeobox proteins, Msx2 and Dlx5. Genes Cells 6:851-856.

Sierra OL, Cheng S, Loewy AP, Charlton-Kachigian N, Towler DA. 2004 MINT, the Msx2 interacting nuclear matrix target, enhances Runx2-dependent activation of the osteocalcin fibroblast growth factor response element. J Biol Chem 279:32913-32923.

Sudo H, Kodama H, Amagai Y, Yamamoto S, Kasai S. 1983. In vitro differentiation and calcification in a new clonal osteogenic cell line derived from newborn mouse calvaria. J Cell Biol 96:191-198.

Taylor SM, Jones PA. 1979. Multiple new phenotypes induced in 10T1/2 and 3T3 cells treated with 5-azacytidine. Cell 17:771-779.

Terkeltaub RA. 2001. Inorganic pyrophosphate generation and disposition in pathophysiology. Am J Physiol Cell Physiol 281:C1-C11.
Terkeltaub R, Rosenbach M, Fong F, Goding J. 1994. Causal link between nucleotide pyrophosphohydrolase overactivity and increased intracellular inorganic pyrophosphate generation demonstrated by transfection of cultured fibroblasts and osteoblasts with plasma cell membrane glycoprotein-1. Relevance to calcium pyrophosphate dihydrate deposition disease. Arthrit Rheum 37:934-941.

Thisse B, Thisse C. 2005. Functions and regulations of fibroblast growth factor signaling during embryonic development. Dev Biol 287:390-402.

Wang D, Christensen K, Chawla K, Xiao G, Krebsbach P, Franceschi R. 1999. Isolation and characterization of MC3T3-E1 preosteoblast subclones with distinct in vitro and in vivo differentiation/mineralization potential. J Bone Miner Res 14:893-903.

Wenkert D, Benigno M, Mack K, McAlister W, Mumm S, Whyte M. 2009. Hypophosphatasia: Prevalence of Clinical Problems in 175 Pediatric Patients. American Society for Bone and Mineral Research 31st Annual Meeting, Denver, C0. Abstract A09001674.

Willis DM, Loewy AP, Charlton-Kachigian N, Shao J, Ornitz DM, Towler DA. 2002. Regulation of osteocalcin gene expression by a novel $\mathrm{Ku}$ antigen transcription factor complex. J Biol Chem 277:37280-37291.

Xiao G, Jiang D, Gopalakrishnan R, Franceschi RT. 2002. Fibroblast growth factor 2 induction of the osteocalcin gene requires MAPK activity and phosphorylation of the osteoblast transcription factor, Cbfa1/Runx2. J Biol Chem 277:36181-36187.

Xue Y, Ren J, Gao X, Jin C, Wen L, Yao X. 2008. GPS 2.0, a tool to predict kinase-specific phosphorylation sites in hierarchy. Mol Cell Proteomics 7:1598-1608.

Zhou Y, Xu X, Chen L, Li C, Brodie SG, Deng C. 2000. A Pro250Arg substitution in mouse Fgfr 1 causes increased expression of $\mathrm{Cbfa} 1$ and premature fusion of calvarial sutures. Hum Mol Genet 9:2001-2008. 